\title{
Metáforas de la multitud en el análisis del movimiento 15 M: la red y el enjambre*
}

\author{
Metaphors of the crowd in the analysis of the movement $15 \mathrm{M}$ : \\ the network and the swarm
}

MIGUEL CORELLA**

\begin{abstract}
Resumen: Las metáforas no son un mero adorno retórico que haga comprensible un concepto abstracto, ni dan nombre a una realidad preexistente, sino que esta operación retórica, dar nombre, cuando se aplica al ámbito de la teoría política, pretende hacer posible la constitución de una identidad de grupo y, con ello, la construcción de un sujeto político. El término multitud es un concepto problemático de la filosofía política contemporánea por lo que autores como Hardt y Negri han recurrido a diversas metáforas para definirlo, metáforas como la red y el enjambre. Por otra parte, algunos de los estudios sobre el Movimiento $15 \mathrm{M}$ y otras nuevas formas de intervención política han hecho uso de estas metáforas trasplantándolas del ámbito de la biología, la teoría de sistemas o la neurología al de la política. En esta traslación algunos supuestos metafísicos, en particular un cierta concepción teleológica de la política se presenta con la legitimidad de la ciencia experimental. Este artículo pretende relativi-
\end{abstract}

\begin{abstract}
Metaphors are not mere rhetorical ornament that makes an abstract concept understandable, or give name to a pre-existing reality, but this rhetorical operation, naming, when applied to the field of political theory, intends to allow the formation of a group identity and thereby build a political subject. The term Multitude is a problematic concept of contemporary political philosophy so authors such as Hardt and Negri have used various metaphors to describe it, metaphors such as network and swarm. Moreover, some of the studies on the $15 \mathrm{M}$ Movement and other new forms of political intervention have used these metaphors transplanting the field of biology, systems theory or neurology to politics. In this translation some metaphysical assumptions, in particular a certain teleological conception of politics have acquired the legitimacy of experimental science. This article seeks to relativize the «scientific» status of the concept presented in these contexts as well
\end{abstract}

Recibido: 25/04/2016. Aceptado: 30/07/2016.

* Este artículo fue realizado con el marco del proyecto de investigación: Ministerio de Economía y Competitivdad. Proyecto de investigación: «El arte de la participación. El uso de las tecnologías de la información como herramienta de creación colectiva en el arte contemporáneo hispanoamericano» (HAR2012-33154).

** Profesor de Estética y Cultura Visual en la Facultad de Bellas Artes de la Universitat Politècnica de València (mcorella@har.upv.es). Sus principales líneas de investigación son las vanguardias artísticas y literarias en Hispanoamérica y las relaciones entre estética y política, en aspectos como la iconografía del poder o la construcción del imaginario político. Publicaciones recientes: (2011) «La política de las imágenes en Jacques Rancière», en Res publica. Revista de filosofía política, $\mathrm{n}^{\circ}$ 26, Madrid, Uniersidad Computense. (2013) «Técnicas del presente. Producción de presencia», en Jean-Luc Nancy, La partición de las artes, Valencia, Pretextos. 
zar el estatuto «científico» con el que se presenta el concepto en estos contextos así como revelar algunos supuestos que se asumen de manera no siempre consciente al enfrentarse a la tarea de dar nombre a lo que ocurre orientándonos en el pensar y en el hacer.

Palabras clave: multitud, retórica política, Antonio Negri, Movimiento15M, sistema-red, tecnopolítica, enjambres. as reveal some assumptions that are assumed not always consciously to face the task of naming what is going to guide us in thinking and doing.

Keywords: crowd, political rhetoric, Antonio Negri, Movement 15M, system-network, technopolitics, swarms.

\section{Metáforas de la multitud}

El término multitud constituye un referente ineludible en el ámbito de la filosofía política al menos desde la publicación del conocido libro de Michael Hardt y Antonio Negri titulado precisamente así, Multitud (Hardt y Negri, 2004). Como estos autores aclaran, el estatuto del concepto es problemático porque no intenta dar cuenta de una supuesta realidad objetiva sino que constituye un proyecto $^{1}$. Proyecto en tanto quiere expresar el deseo de lograr una sociedad con mayores cotas de democracia y proyecto también porque pretende proporcionar los medios para alcanzarla. El término tiene, por tanto, un carácter performativo y, lejos de dar nombre a una realidad preexistente, se propone dar forma a una posibilidad por venir. En el intento de diseñar este concepto político (y también este proyecto político) las metáforas juegan en la obra de Negri y Hardt un papel muy importante, particularmente la metáfora de la $\mathrm{red}^{2}$. Y es que una misma estructura en red constituirá la lógica organizativa del poder económico y político en la era del Imperio, un auténtico poder en red (Hardt y Negri, 2004, 14), al que correspondería una red igualmente global de circuitos de cooperación y colaboración, una red que proporciona los medios de encuentro que nos permitan trabajar y vivir en común (Hardt y Negri, 2004, 16). La misma metáfora de la red sirve pues para describir la estructura económica del nuevo capitalismo y la posibilidad de que los múltiples actos de resistencia al mismo puedan conectarse para generar una alternativa. Las metáforas no son pues un mero adorno retórico que haga comprensible un concepto abstracto, ni dan nombre a una realidad preexistente, sino que esta operación retórica, dar nombre, pretende hacer posible la constitución de una identidad de grupo y, con ello, la construcción de un sujeto político (Laclau, 2005, 34).

Por otro lado, mientras que los conceptos aspiran a la claridad y distinción para tener un significado preciso y fijo, las metáforas se caracterizan por su constante mutación. Como demostró Aby Warburg estas no obedecen al tiempo continuo del progreso constante

1 La aclaración está en las primeras líneas del prefacio a Multitud, titulado «Vida en común»: La posibilidad de la democracia a escala global emerge hoy por primera vez. Este libro trata de esta posibilidad, de lo que vamos a llamar «proyecto de la multitud». Un proyecto que no sólo expresa el deseo de un mundo de igualdad y de libertad, no solo exige una sociedad global democrática abierta e inclusiva, sino que proporciona los medios para conseguirla (Hardt y Negri, 2004, 13).

2 De nuevo acudimos al símil de una red distribuida, a internet, como imagen o modelo para una primera explicación de la multitud (Hardt y Negri, 2004, 13). 
sino que saltan hacia atrás para recuperar imágenes del pasado que al actualizarse cambian en su significado. Las metáforas resucitan o retornan desde el pasado trayendo al presente los viejos fantasmas y proyectando hacia el futuro posibilidades que quedaron al margen de la historia, historia siempre de los vencedores. Es así como, para explicar aquella otra metáfora de la multitud, Hardt y Negri recuperan viejas imágenes de la antigüedad griega y latina como la del clinamen $^{3}$. Es sintomático que el libro que venimos citando se cierre comparando el movimiento de la multitud con el concepto de clinamen, entendido como la oportunidad (kairos) en que, a partir de la acumulación de decisiones particulares y cooperativas, se podrá generar la ruptura con el orden establecido ${ }^{4}$.

Pero las mutaciones de las metáforas no sólo se dan en el tiempo sino que estas saltan de un campo a otro del saber en un movimiento de continua ida y vuelta: de la biología, la sociología o la teoría de la información a la esfera política o de la producción artística. En este artículo revisaremos el uso de las metáforas de la red y el enjambre en un libro reciente, cuyo interés radica en que pretende dar cuenta del conocido como Movimiento $15 \mathrm{M}$ recurriendo a la metáfora de la multitud (Toret, 2013). Como veremos, sus autores echan mano de las metáforas de la red y el enjambre en una constante traslación de sentido de las mismas del ámbito de la biología, la teoría de la información o la matemática al territorio de la filosofía política. Nuestra intención será relativizar el estatuto «científico» con el que se presenta el concepto en estos contextos así como revelar algunos supuestos que asumimos de manera no siempre consciente a la hora de enfrentarnos a la tarea de dar nombre a lo que ocurre orientándonos en el pensar y en el hacer.

\section{Mutaciones de la metáfora: de la red al enjambre}

La red no sólo constituye, como hemos visto, la metáfora de inicio que utilizan Hardt y Negri para explicar el concepto de multitud, sino que también, en opinión de los autores, organiza nuestra visión del mundo contemporáneo, ya que, como afirman: se ha convertido en una forma común que tiende a definir nuestra manera de entender el mundo y de actuar dentro de él (Hardt y Negri, 2004, 174). Como también señalábamos, el nombre aspira a identificar o, mejor, a dar identidad, a nuevo sujeto político en construcción que sustituye a la clase obrera, sujeto que correspondía al viejo capitalismo fordista y que ahora se ha difuminado con la globalización de la economía. La condición de posibilidad para dar cuenta de un modo unitario tanto de los nuevos modos de dominación como de las nuevas formas de resistencia es un diagnóstico del actual modo de producción en el que la plusvalía ya no se generaría en términos de tiempo de trabajo abstracto y cuantitativo, sino como expropiación de un conocimiento surgido de habilidades comunicativas y emocionales que son patrimonio del común. De acuerdo en buena medida con el análisis de Paolo Virno (2003), Hardt y Negri convendrían en que la plusvalía se origina en la

3 Antes de la publicación de Multitud Negri había estudiado con detenimiento está metáfora del clinamen (Negri, 2000) a la que volvería con posterioridad (Negri, 2005).

4 La práctica política revolucionaria debe saber captar en el movimiento de la multitud, y a través de la acumulación de decisiones comunes y cooperativas, el momento de ruptura o clinamen capaz de crear un mundo nuevo (Hardt y Negri, 2004, 405). 
expropiación de un valor común constituido por las facultades lingüístico-comunicativas comunes a la especie, aquello que Virno $(2003,42)$ denominaba general intellect ${ }^{5}$.

Al explicar el sentido de este intelecto común, Hardt y Negri recurren a metáforas biológicas creyendo encontrar en las ciencias naturales una validación de sus propias teorías políticas. Así afirman que: Parece como si algunos desarrollos científicos siguieran un camino paralelo al de nuestras propias reflexiones (Hardt y Negri, 2004, 383). Los autores no aclaran cuáles son estos aportes que confirmarían sus hipótesis, pero puede que uno de ellos tenga que ver con el recurso a la metáfora del enjambre, tomada del ámbito de la biología, pero muy fructífera en la tradición literaria y en la filosofía política. En el capítulo «La inteligencia del enjambre» Hardt y Negri abordan la idea del intelecto común (general intellect) recurriendo a metáforas como el hormiguero, el enjambre y la bandada de pájaros ${ }^{6}$. Sin embargo, pájaros, hormigas y abejas obedecen en sus desplazamientos a las leyes del instinto y siguen una línea y una trayectoria preestablecidas, por lo que siguen siendo inapropiadas para dar cuenta de la libertad de acción de cada uno de los miembros de la multitud. Por ello nuestros autores plantean una cautela destinada a impedir cualquier interpretación teleológica y afirman: No desearíamos dar la impresión de que las formas de resistencia se suceden con arreglo a alguna evolución natural o línea preestablecida (Hardt y Negri, 2004, 122). La metáfora sirve entonces como tal y expresa un cierto grado de semejanza entre los términos de la comparación, por lo que la prevención de Hardt y Negri pretende evitar cualquier forma de evolucionismo o determinismo. ¿Mantienen los autores del estudio sobre la red del 15M las mismas cautelas? Antes de abordar esta cuestión conviene revisar brevemente la deriva de la metáfora del enjambre en la filosofía política.

\section{La metáfora del enjambre}

La metáfora del enjambre o del panal de abejas, muy lejos de ser nueva, tiene un largo recorrido en la filosofía política que, desde sus orígenes, hubo de recurrir a las fábulas para explicar el funcionamiento de la comunidad y para hacer verosímiles sus propuestas utópicas. Sin duda el libro de Bernard Mandeville, La fábula de las abejas (1714) constituye un importante eslabón de esta cadena de metáforas zoológicas ${ }^{7}$. El libro es una provocativa

5 Encontramos una explicación sencilla de esta tesis en el prefacio a Multitud: El propio trabajo tiende hacia las transformaciones de la economía para crear y ser absorbida en redes de cooperación y comunicación. Todas las personas que utilizan en su trabajo la información y el conocimiento (...) se apoyan en el acervo común del conocimiento que han recibido de otros, y crean a su vez nuevo conocimiento común (Hardt y Negri, 2004, 18). La idea se desarrolla en el capítulo «Excurso I: Método: tras las huellas de Marx» (ibid. 172 ss.)

6 Como la red no tiene un centro que dicte las órdenes, los que solo piensan de acuerdo con los modelos tradicionales creen que no hay organización de ninguna especie y solo ven espontaneidad y anarquía. El ataque en red se compara con las bandadas de pájaros o de insectos de las películas de terror: una multitud de asaltantes necios, desconocidos, inciertos, ocultos e inesperados. Pero si se contempla el interior de una red, se observa que sí hay organización, racionalidad, creatividad. Es la inteligencia del enjambre (Hardt y Negri, 2004, 120-121).

7 El libro, que tuvo varias ediciones con diversos añadidos en vida del autor, recogía un poema publicado por Mandeville en 1705 y titulado The Grumbling Hive, or Knaves Turn'd Honest. La moraleja de la fábula está enunciada en el título, pues el libro lleva a la conclusión de que de la satisfacción de los vicios privados resulta 
fábula poética ante la que tuvieron que posicionarse filósofos de la talla de Berkeley o Locke. El panal rumoroso, título con el que Alfonso Reyes tradujo libremente el poema de Mandeville, era la metáfora que daba cuenta de la estructura social, de manera que el rumor o el ajetreo constante del enjambre de abejas equivaldría al movimiento de los súbditos del reino. Pero, a diferencia de la interpretación actual del enjambre, Mandeville no resalta tanto el orden de la trama de relaciones que organiza el panal como su aparente desorganización de la que, sin embargo, resulta la prosperidad de la res publica. La moraleja de la fábula podría resumirse diciendo que la prosperidad del reino no puede lograrse, en contra de lo que el filósofo platónico creería, con la imposición de normas morales, judiciales o administrativas, por bienintencionadas y racionales que fueran. Muy al contrario, la aplicación de estas normas generaría, en una perfecta conversión de la utopía en distopía, la ruina de la res publica. Dicho de otro modo, si nos dejáramos llevar por las intenciones moralistas, el ajetreo desordenado de la colmena y su movimiento lleno de vida se convertiría en la parálisis absoluta de la sociedad. El progreso social depende así del movimiento, del zumbido o rumor constante y del hormigueo sin fin de los ciudadanos que, deseosos de dar satisfacción a todos sus apetitos, se someten a una laboriosidad virtuosa. De los vicios privados resultaría así el beneficio público, el bribón se convertiría en honesto y la insociabilidad generaría un aumento de la sociabilidad en un modelo de integración social que renuncia a la imposición normativa y disciplinaria como estrategia para garantizar el progreso social. La fábula del panal ruidoso vendría a demostrar el fracaso del modelo de integración normativa y la mayor eficacia del laissez-faire, en la confianza de que del movimiento libre de cada una de las abejas resultará el progreso económico y la paz social. Por ello podríamos decir, recurriendo a términos de la sociología contemporánea, que el modelo de integración social propuesto provocativamente por Mandeville es de carácter funcionalista. En aras del equilibrio funcional del sistema el filósofo político puede disculpar tanto las conductas inmorales como las diferencias sociales resultantes de la división del trabajo, dado que la distribución de la riqueza resultante acabaría convirtiendo a todas las abejas (obreras, soldados, zánganos o reinas) en ciudadanos libres y relativamente iguales.

La sociología contemporánea recupera este funcionalismo de Mandeville de modo que la eficacia de los vínculos sociales colaborativos no dependería de su grado de integración normativa y coercitiva, de la estabilidad de los lazos o redes que vinculan a los particulares ni de la rigidez de los vínculos entre ellos, sino, justo al contrario, se lograría a través de asociaciones débiles e inestables. La fuerza de los lazos y redes sociales dependería del carácter concreto e inmediato de los fines que los originan. Su utilidad o eficacia derivaría del hecho de ser respuesta a una necesidad y surgir de una situación que hace de la colaboración la mejor opción. Por otra parte, la eficacia estratégica de la colaboración no requeriría la participación voluntaria y consciente de los particulares, de cuyas acciones libres y caótico hormigueo resulta una acción coordinada regida por una mano invisible. Poco importa que la organización en que finalmente redunda el caos sea expresión de un supuesto orden natural, de un dios omnisciente o de las leyes de la economía, pues en un caso u otro el supuesto

el beneficio público. También el título del poema plantea la tesis de que el bribón, persiguiendo su propio beneficio y sin consideración alguna de las normas morales y reglas de ciudadanía, se transforma a la postre en honrado ciudadano en virtud de algún mecanismo tan seguro como invisibe. 
esencial es la confianza en que el sistema se autorregula para mantenerse en equilibrio. De este principio incuestionable se derivan dos ideas fundamentales íntimamente relacionadas: de un lado la creencia en que el sistema funciona sin necesidad de que los partícipes asuman compromisos morales o ideológicos de cualquier tipo; de otro, la convicción de que cualquier intervención que altere el equilibrio sistémico, por moralmente correcta que sea, generará efectos indeseables y es, por tanto, disfuncional al sistema. En consonancia con esos supuestos la fábula de Mandeville permite concluir que resulta perjudicial para el reino la imposición de principios normativos y que es mucho más eficaz permitir el libre y natural establecimiento de vínculos sociales basados en la persecución de los deseos e intereses de cada cual. La máxima «vicios privados, beneficio público» es equivalente pues a la de «vínculos débiles y unión fuerte». La integración social será más eficaz si nace espontáneamente del intercambio entre particulares encaminado a satisfacer intereses y deseos circunstanciales que si surge de la existencia de grupos sociales compactos, rígidos y estables.

Este es precisamente el supuesto ideológico o, si se prefiere, la conclusión teórica del capítulo titulado «Del enjambre a la conciencia de red: el sistema red como mente colectiva» del libro, también colectivo, Tecnopolítica: la potencia de las multitudes conectadas (Toret, $2013)^{8}$. El capítulo comienza por afirmar que el movimiento $15 \mathrm{M}$ se caracteriza por haber surgido de procesos de comportamiento colectivo no basados en organizaciones sociales constituidas ni en identidades o vínculos fuertes (Toret, 2013, 105). Se trata por tanto de una forma de organización social de vínculos débiles y que, precisamente por ello, genera una unión extraordinariamente fuerte. El propósito del trabajo será explicar esta aparente paradoja o, como se afirma, esclarecer la magia y «la fuerza de los vínculos débiles», expresión que toman de Granovetter (1974), y mostrar cómo esta nueva forma de organización colectiva modular y reconfigurable constituye lo que con Rheingold (2004) denominan una multitud inteligente, es decir, un grupo capaz de sincronizar sus acciones en tiempo real y de forma instantánea con la finalidad de defender o atacar a un enemigo, para conseguir un objetivo específico (Rheingold, 2004, 106). Para dar cuenta de la eficacia de estas organizaciones débiles en comparación con las configuradas por una identidad fuerte recurren al término swarming que toman de John Arquilla y David Ronfeldt (2001) ${ }^{9}$. El swarming, que podemos traducir literalmente por enjambramiento, explicaría el tipo de vínculos comunitarios propios de movimientos políticos como el $15 \mathrm{M}$ que los autores definen como formaciones que emergen en torno a lo que acontece y que se cuasi-organizan a partir de la fuerza de los vínculos débiles y agrupaciones temporales de intereses y deseos.

8 El título del capítulo que comentamos (105ss) no corresponde con el que aparece en el índice, que propone este otro: «Enjambres. El arte de la organización en red: sincronización multicapa y tipologías de comportamiento colectivo en el $15 \mathrm{M} »$.

9 Aunque no se da una referencia concreta, debe tratarse del libro de Arquilla y Ronfeldt. Swarming and the Future of Conflict. John Arquilla, experto en relaciones internacionales y en estrategia militar, fue miembro del prestigioso instituto de investigación RAND y asesor del general Norman Schwarzkopf así como del secretario de defensa del gobierno de Georg W. Bush, Donald Rumsfeld. Ronfeldt, profesor Universidad de Stanford, es experto en terrorismo y operaciones de información y defiende la idea de que la sociedad contemporánea se organiza a partir del modelo de la red, tal como en eras anteriores lo hacía en torno a estructuras sociales tales como la tribu, las instituciones jerárquicas o los mercados. 
La metáfora del enjambre tal como la usan Arquilla y Ronfeldt es equivalente a la de la red, desarrollada por ellos mismos en su libro Networks and Netwars (Arquila y Ronfeld, 2001). Este estudio propone un análisis de las nuevas amenazas militares para los EEUU, tanto internas como externas, del que se concluye que en la era de las comunicaciones en red (Networks) la guerra ya no enfrenta a ejércitos y es también una guerra en red (Netwars). La red constituye una estructura que se repite en diferentes ámbitos y así hablamos de economía en red, comunicaciones en red o guerra en red. En lo que respecta a las amenazas para la seguridad la red es la estructura que caracteriza tanto a los grupos terroristas islamistas como a los grupos antisistema de tradición anarquista, ecologista o activista que luchan por los derechos civiles y democráticos. Unos y otros tendrían en común el organizarse en pequeños grupos dispersos que se despliegan con rapidez en cualquier lugar y en cualquier momento. En definitiva, el diagnóstico de Arquilla y Ronfeldt permite reconocer que una misma estructura en red caracteriza a las principales formas de oposición política y militar al sistema, por lo que recomiendan formas de defensa y de respuesta por parte de la sociedad civil global estructurada en red. La red es por tanto la estructura universal, común al sistema económico-social dominante y a las formas de resistencia al mismo, de modo que lo que constituye una eficaz arma en manos de los opositores se revela también como la mejor estrategia de defensa. El supuesto de que una misma estructura en red organiza el sistema en su conjunto, incluyendo tanto la lógica de la dominación política institucional como la de los movimientos de resistencia a la misma, se extiende más allá del ámbito de la política y la sociología del conflicto para buscar en las ciencias (la biología, la matemática, la teoría de la comunicación) nuevos argumentos que revalidan la tesis principal. Es lo que podríamos denominar una ontología del sistema-red que convierte lo que en principio era una metáfora en estructura ontológica de lo real.

El estudio del movimiento $15 \mathrm{M}$ propuesto por el grupo Datanalysis se apropia de la doble metáfora enjambre-red propuesta por Arquilla y Ronfeldt buscando en las ciencias naturales la confirmación de sus supuestos básicos. Uno de sus argumentos consiste en recurrir a la biología para dotar a las nuevas formas de activismo político de una fundamentación ontológica. Esto les lleva a proponer analogías entre el comportamiento de la multitud que se moviliza a través de las redes sociales y el de formas de organización biológica de especies como las abejas o las hormigas. Sin embargo y como ellos mismos aclaran, la comparación con las hormigas y abejas no es del todo correcta por tratarse de grupos fuertemente jerarquizados mientras que las nuevas comunidades políticas on-line conformarían una especie de enjambres sin abeja reina. Si esta transformación de la metáfora del enjambre intenta salvar el peligro del dirigismo político y diferenciar las nuevas formas organizativas respecto de las viejas estructuras partidistas de la tradición socialista, la idea de un enjambre imprevisible pretende sortear el peligro de concebir la acción política como un movimiento teleológico dirigido hacia alguna meta que sólo la abeja reina conocería o que estuviera marcada por alguna suerte de necesidad natural. La metáfora zoológica muestra también sus debilidades si pensamos en imágenes similares tomadas de algún otro reino animal, tales como los bancos de peces o las bandadas de pájaros. Como se afirma en el texto que comentamos: las manadas tienen un jefe, las bandadas no (...) Comprender el fenómeno de toma de decisiones de la bandada de pájaros es interesante para pensar cómo ha sido el patrón de comportamiento colectivo del sistema-red 15M. Pero, en definitiva y aunque 
la mutación en la metáfora nos permite concebir una comunidad de iguales, sigue siendo ineficaz para dar cuenta de la idea de una comunidad libre, es decir, no regida por lo que Jacques Rancière definió como una teleología inmanente (Rancière, 2002). La metáfora zoológica se eleva así al rango de patrón de comportamiento introduciendo por la puerta de atrás una auténtica teleología inmanente.

La declarada voluntad de comprender el proceso de toma de decisiones de la multitud y sus patrones de comportamiento responde a aquella máxima fundacional de la sociología formulada por Comte en la primera lección de su Curso de filosofía política (1830): Savoir pour prévoir, afin de pouvoir. Es por esto que el término tecnopolítica da título al trabajo del grupo Datanalysis15M, pues el supuesto de que la multitud traza un movimiento coordinado y teleológico está encaminado a fundamentar la posibilidad de una acción instrumental. Si con las herramientas de la ingeniería y la arquitectura de datos podemos conocer y prever la formación de una inteligencia común estaremos en condiciones de intervenir en estos procesos para dirigir a la multitud hacia algún lugar sometiendo su movimiento a nuestra voluntad de poder. La cuestión crucial en todo esto es que esta voluntad política ha de quedar oculta tras la apariencia de que el movimiento de la multitud obedece a una regularidad empíricamente contrastable y es aquí donde las metáforas biológicas juegan un papel fundamental. La analogía entre las ciencias sociales y las naturales permitirá de este modo demostrar que la multitud responde con eficacia instrumental y de manera cuasi-automática, siguiendo las leyes de la evolución adaptativa al medio, generando respuestas ante las amenazas, respuestas «naturales» 0 «automáticas» en las que no interviene la voluntad y el pensamiento racional.

No debe extrañarnos que, inspirado como está por Arquilla y Ronfeldt, el argumento que venimos resumiendo recurra a una metáfora militar afirmando que el vínculo creado en el enjambre se justifica por la necesidad de defenderse frente a las agresiones de elementos externos. En una variante de la máxima la unión hace la fuerza se afirma ahora la tesis de que los vínculos débiles configuran una unión fuerte. Por vínculo débil podemos entender, a la manera de Mandeville, que la libertad de movimiento de las abejas es la garantía de la eficacia de una integración social no regulada de forma normativa y coercitiva sino asentada en la persecución de su propio interés. Así vemos cómo se resalta en la definición del swarming el supuesto de que la unión del enjambre depende del carácter específico de los objetivos que se propone y tiene carácter instrumental o técnico (tecnopolítico).

La conclusión final de este datanálisis del movimiento $15 \mathrm{M}$ sería que es posible una acción política organizada y por tanto eficaz que se ejerce sobre una finalidad muy concreta y específica, eficacia que deriva del tipo de lazos débiles, plurales, cambiantes y horizontales que caracterizan a las comunidades en red. La tecnopolítica se diferenciaría con esto de otras formas posibles de acción política y de vínculo comunitario. El tipo de acción que se define por su eficacia tecnopolítica no agotaría las posibilidades que ofrece la red, entre las que estarían diversas formas de comunidad no organizadas en torno a una finalidad. Estas se caracterizarían por ser deseables en sí mismas, guiándose por el placer de contactar o compartir. Esta distinción abre la posibilidad de definir otras formas de acción política, metapolítica o archipolítica, así como formas éticas o estéticas de comunidad. 


\section{Conexiones, ecosistemas, fractales y sistemas autopoiéticos}

Como señalábamos, es esencial al modelo de integración social de Mandeville la idea de que el movimiento de la multitud como un todo es independiente de la voluntad consciente de los múltiples particulares que la conforman. Del mismo modo, el intento de explicar el nuevo activismo político y la potencia de las multitudes conectadas partirá de la metáfora del enjambre sin reina, en el que del ajetreo de las abejas resulta el progreso del panal. Esto permite introducir el supuesto de que, análogamente, los sistemas sociales se autorregulan transformando la multitud de movimientos en el movimiento único de la multitud. Tanto en el panal rumoroso de Mandeville como en la multitud conectada del grupo Datanalysis el sistema se autorregula sin necesidad de que las abejas o ciudadanos intervengan conscientemente con la voluntad de contribuir al progreso del colectivo.

Lógicamente, el primer paso que permitirá concluir después la existencia de un sistema social autorregulado será superar los «viejos modelos» de la conciencia individual ${ }^{10}$. Frente a lo que se califica como nociones pantanosas de la conciencia ideológica o de la conciencia moral el sujeto protagonista del movimiento $15 \mathrm{M}$ sería un proto-self, un sujeto colectivo o transindividual, construido a partir de emociones. Esta confusa terminología se aclara un tanto cuando los autores de este trabajo colectivo recurren a un muy exitoso libro de divulgación científica (Hölldobler y Wilson, 1990) para llevarnos de nuevo a la metáfora de las hormigas: Las hormigas se comunican (...) con señales semio-químicas a través de la intensidad de las feromonas que desprenden. Del mismo modo, puede quizá afirmarse que las mentes conectadas lanzan y reciben diversas señales info-emocionales, cognitivo-emotivas que permite la organización de la cooperación (Toret, 2013, 92). Los nuevos movimientos políticos se explican, pues, a partir de un modelo cognitivo-emotivo que no sólo reconoce que las emociones son una forma de conocimiento, sino que parece reducir la cognición a emoción (excluyendo del ámbito de la política cualquier mención a la voluntad racional como si de una falsa envoltura ideológica se tratara) y que confía en que una inteligencia grupal e instintiva es capaz de llevar a cabo los ajustes que el sistema requiere.

Esta toma de partido metodológica permite a Datanalysis emprender un estudio semántico de los hashtags en twitter que reduce el lenguaje a sus aspectos puramente expresivos, detectando mediante el análisis de datos, la presencia de emociones como la indignación, la rebeldía, el empoderamiento, la alegría o la rabia. Sin duda los resultados de este estudio ofrecen datos muy interesantes para conocer los flujos de difusión de mensajes, las personas o colectivos más influyentes en su propagación y toda suerte de estudios estadísticos. ¿Quién puede negar la importancia de las emociones en la formación de las opiniones políticas? Pero, obviamente, el lenguaje es algo más que la pura expresión de emociones; es también la capacidad de enunciar un sentido compartido y de construir metáforas, símbolos y con-

10 Recurriendo a varias fuentes secundarias que parecen basarse en el libro de Antonio Damasio (2003), se afirma que el análisis del sistema red 15M se lleva a cabo desde la teoría experimental de la conciencia. Esta se resume en términos bastante confusos como el sentimiento de lo que acontece por parte de un organismo metaestable u organismo colectivo híbrido y compuesto que construye un proto-self (hecho de señales y emociones que remiten a un cuerpo común emergente), permite anteponer esa conciencia intensiva y transindividual del sistema autopoiético en su proceso de autoproducción a toda asimilación a las nociones pantanosas de la conciencia ideológica o de la conciencia moral. (Toret, 2013, 89). 
ceptos que sirvan para orientarnos en el hacer. Decir, como los acampados en la plaza del Sol de Madrid, «no nos representan», es algo más que expresar descontento o indignación, es afirmar la capacidad de todos y cada uno para ser sujeto pleno de la deliberación política; es exigir formar parte de ese reparto del poder; es en definitiva la exigencia de tener voz en el debate político, pero voz articulada y no simple expresión emocional de rabia o de júbilo.

Sin embargo, el estudio de Datanalysis insiste en muchos de sus capítulos en el esfuerzo de definir el nuevo sujeto político, la multitud conectada, como una agrupación cuya fortaleza depende del establecimiento de vínculos emocionales y no racionales. Así el capítulo que ya comentábamos afirma que el movimiento de la multitud poco tiene que ver con cómo pensamos procesos deliberativos y racionales (Toret, 2013, 116). La multitud se mueve como resultado, se afirma también, de una dinámica de respuestas emocionales, por lo que su funcionamiento podría entenderse por analogía con fenómenos naturales como los terremotos, rayos, tornados y otras formas de liberación de la energía acumulada. Vemos con esto cómo la argumentación permite saltar del ámbito de la psicología de las masas al territorio mucho más abstracto y genérico de la teoría de sistemas. Lo que de común encuentran los autores del estudio entre la dinámica de las respuestas emocionales y los grandes fenómenos naturales es la idea de que obedecen a una dinámica o una economía de la carga y la descarga que permite al sistema (físico, zoológico, psicológico o sociológico) mantener el equilibrio del todo gracias al papel regulador de los desequilibrios en las partes. Así puede afirmarse que por mente colectiva hemos de entender la existencia de mecanismos de autorregulación como los que en los sistemas de flujos energéticos, son capaces de lograr la permanencia en el tiempo gracias a fenómenos de carga y descarga (Toret, 2013, 117). Por ello mismo se hace posible saltar a una nueva metáfora para proponer que muchos fenómenos físicos asociados a la disipación de energía se configuran en estructuras fractales (Toret, 2013, 118). La estructura fractal sería el modelo geométrico a la base de fenómenos muy diversos, todos ellos organizados a partir de una forma básica o patrón que, como las celdas de un panal de abejas, se repite a diferente escala permitiendo el crecimiento y dotando al sistema de una mayor complejidad.

La más simple de estas estructuras sería sin duda la línea que conecta dos puntos cualesquiera y que puede multiplicarse ad infinitum para crear lazos, nudos, redes y entramados cada vez más complejos. Esta metáfora básica de la conexión se aplica a campos tan diversos como la biología, la teoría de la información y de las señales (eléctricas, químicas...) y en general a la teoría de sistemas. Sin duda la aparición de internet ha cargado de actualidad esta metáfora que no por casualidad da nombre a este nuevo medio de comunicación digital: la red tejida por múltiples conexiones en línea. Pero si el nuevo medio ha tomado el nombre de viejas metáforas, también ocurre que las ciencias de la era informática encuentran en la red una confirmación de sus presupuestos teóricos y creen reconocer en ella la existencia de un paradigma que legitima campos muy diversos del saber. Bastará con algunos ejemplos de noticias que provienen del periodismo científico y que, por su simplicidad, revelan las metáforas e intuiciones básicas que inspiran el desarrollo de las teorías científicas.

El primero de estos ejemplos está tomado de la sección de ciencias del periódico El País (Domínguez, 2014a) y comparte alguno de los supuestos básicos del grupo Datanalysis15M. En primer lugar la convicción de que una misma estructura rige el funcionamiento de la 
conexiones neuronales y de gran parte de las redes artificiales como las eléctricas o las de comunicación. En segundo lugar la idea de que las catástrofes que a menudo se producen en estos sistemas de señales se deben a fallos en la red de conexiones. Finalmente y aunando las dos primeras supuestos, se concluye que el estudio del cerebro y de las enfermedades o trastornos en las conexiones neuronales puede darnos las claves para evitar las catástrofes en las redes de comunicación evitando errores en las conexiones. Los titulares del artículo resumen la idea de forma muy periodística afirmando que tus neuronas mejorarán las redes que mueven el mundo y que los investigadores proponen imitar las redes neuronales para evitar catástrofes y para mejorar otras redes artificiales. Se recurre a la autoridad de Santiago Canals, del Instituto de Neurociencias de Alicante, para exponer la hipótesis de que hay enfermedades neurológicas o psiquiátricas achacables a malas conexiones que reorganizan el cableado del cerebro y se emprenden experimentos con animales para comprobarlo. Finalmente y recogiendo la opinión de Florentino Borondo, del Instituto de Ciencias Matemáticas, se llega a la conclusión de que un mismo modelo matemático puede dar cuenta tanto de las redes sociales o de amigos como de las redes biológicas.

El segundo ejemplo nos lo proporciona también el citado suplemento del diario El País y ha sido reproducido por diversas revistas de divulgación científica (Domínguez, 2014b). Se trata de una entrevista al profesor de Neurociencia Computacional y de Física del Massachusetts Institute of Technology Sebastian Seung. El título resulta muy sugestivo: Tenemos que explicar cómo una red de neuronas tontas es capaz de producir inteligencia, y representa una llamativa actualización del problema que se planteara Mandeville. Efectivamente si la inteligencia humana es el resultado del trabajo de millones de neuronas que, como las abejas de Mandeville, van a lo suyo sin considerar el interés general del panal, tenemos fundadas razones para confiar en que, de la multiplicidad de movimientos tontos de los ciudadanos, resultará el movimiento inteligente de la multitud. Como en el ejemplo anterior, también el modelo de Seung concede la mayor importancia a la conexión entre las neuronas, lo que le lleva a proponer la idea de conectoma por analogía con el concepto de genoma. El mismo Seung resume esta teoría con la frase Soy mi conectoma, sentencia que hemos de entender en el sentido de que no somos tanto nuestro genoma o, lo que es lo mismo, nuestro contenido informacional, sino que somos más bien nuestras conexiones. Extendiendo esta idea quizás pudiéramos decir que no somos tanto un patrimonio genético heredado que nos determina en parte, sino que son nuestros contactos o nuestra capacidad para mantenerlos lo que nos define.

La analogía entre la estructura conectada de internet y la de nuestro cerebro ha llevado a Seung a proponer la elaboración de un mapa de nuestro conectoma gracias a la colaboración de miles de internautas a través de la plataforma online EyeWire (eyewire.org). Esta se presenta al potencial colaborador como un juego que cuenta ya con la participación de más de 150.000 personas y se le ofrecen especiales oportunidades de participación en la Happy Hour, todos los viernes de 2-4 pm en el horario ET estadounidense. Cada uno de los participantes actúa como una neurona tonta capaz, sin embargo, de producir inteligencia. Para ello se le encarga rastrear las conexiones de una sección plana de neurona lo que, sumado al trabajo de otros miles, acabará generando un mapa tridimensional. 
Los esfuerzos de la neurología por explicar el surgimiento de respuestas inteligentes y colectivas a partir de las respuestas tontas de elementos singulares inspira en gran medida, como venimos viendo, la propuesta de una tecnopolítica capaz de dar cuenta de la inteligencia colectiva de la multitud conectada. Así ocurre en el capítulo titulado «Emociones colectivas y lenguaje» escrito por Óscar Marín (Toret, 2013, 69-85). Aquí también se parte de un análisis de las emociones movilizadas en el $15 \mathrm{M}$, pero la novedad radica en el recurso a la teoría de la autopoiesis, enunciada por Maturana y Varela (1973). Según estos biólogos chilenos la vida consiste, si se analiza a partir del metabolismo celular, en una constante interrelación con el medio. Por ello todo ser vivo puede entenderse como un sistema en el que la multitud de células es capaz de dejarse afectar por el mundo y también de afectarlo gracias a la interacción mutua. De este modo, el organismo puede entenderse como un sistema capaz de autoproducirse (autopoiesis) en ausencia de una dirección central.

La relación de intercambio entre el organismo vivo y el mundo así como su capacidad para adaptarse a las circunstancias y modificarlas bastaría para explicar el funcionamiento de los seres vivos como una inteligencia colectiva en ausencia de una cabeza pensante. Esta idea de autopoiesis adaptativa y relacional es análoga a aquellas otras de la colmena sin abeja reina o del panal rumoroso y sirve para legitimar el supuesto de que la multitud conectada funciona como una inteligencia colectiva y acéfala capaz de autorregularse gracias a la interacción entre sus miembros. Esto permite a Óscar Marín concluir proponiendo que el movimiento $15 \mathrm{M}$ (y la acción política de la multitud conectada en general) funciona como un ecosistema. El 15M, como cualquier sistema-red, funcionaría como un ecosistema en el sentido de que, en primer lugar, tiene una estructura abierta, policéntrica, marcada por la cooperación entre nodos. El segundo rasgo que define este ecosistema cultural y político sería el hecho de que, como organismo vivo y mutante, cuenta con la capacidad de dar una respuesta adaptativa al medio así como de generar respuestas que alteran las circunstancias externas. Por último, la estructura del ecosistema permitiría superar el modelo cartesiano del sujeto y la distinción consecuente entre res cogitans y res extensa, ya que un cuerpo común, es decir, una res extensa sin res cogitans o cabeza pensante que la rija, actuaría como sujeto colectivo de conocimiento y de acción. Como ya señalábamos, este nuevo sujeto de la acción cognitiva y política estaría constituido como un protoself, hecho de señales y emociones antes que de intuiciones racionales claras y distintas. Jugando con los términos de Descartes diríamos que frente a la vieja máxima pienso luego existo, el nuevo sujeto colectivo, la multitud, se definiría a partir de la sentencia siento luego existo.

\section{El autómata de Kempelen: teleología inmanente}

Hemos visto diversas metáforas que nacen del intento de encontrar un sentido o una dirección en el movimiento de la multitud. Su pretensión es la de reducir la multiplicidad de movimientos singulares a un movimiento de la multitud en una dirección previsible y que, justo por ello, permite al tecno-político intervenir para acelerarlo o retardarlo. La posibilidad de una tecnopolítica se basa en esta confianza en que, si podemos prever el sentido que el zumbido aparentemente caótico del panal delinea, estaremos en condiciones de intervenir sobre él. Con ello la nueva tecnopolítica hace suya la pretensión fundacio- 
nal de la sociología tal como la entendió Comte: saber para prever, prever para poder. Sin embargo este impulso fáustico, por mucho que resulte constitutivo para la condición humana, no debe perder de vista nunca sus propios límites. Y es que, en primer lugar, nos enfrentamos a lo que es una mera desiderata que no ha dejarse llevar por la tentación de la omnipotencia. No todo es previsible ni se pliega a las condiciones puras de la economía o ecología del sistema. Es por esto que la segunda prevención nos aconseja tener presente siempre que reducir lo real en su multiplicidad y singularidad a aquellas variables sobre las que nos está permitido intervenir técnicamente no es más que una esperanza dictada por la urgencia de la acción. Por mucho que parezca obvio hemos de recordar que si nuestro deseo de conocer se supedita a nuestra voluntad de poder hacemos oídos sordos a la tozuda presencia de lo real.

El modelo teórico que hemos visto viene a sostener que la multitud se mueve con una finalidad propia regida por leyes de la biología o por procedimientos de autorregulación, como si se tratara de un sistema-red. Sin embargo debemos entender estas propuestas no como tesis probadas (por mucho que se recurra a la mano invisible de un supuesto ecosistema y a la legitimidad de la ciencia) sino, en todo caso, como lo que Kant llamaba «una perspectiva consoladora de futuro». Si queremos que nuestras buenas intenciones a la hora de actuar tengan alguna oportunidad de futuro y que nuestros esfuerzos sean recompensados, necesitamos creer que la realidad tiende hacia un cierto progreso. Si apostamos por una idea de comunidad que, a diferencia del panal rumoroso de Mandeville, sea algo más que el mero resultado de acciones individuales ciegas, deberemos sentar las condiciones de posibilidad de esta acción comunitaria. Pero esta creencia no puede ser dogmática ni utópica (pues toda utopía encierra el peligro de una distopía), sino que debemos tomarla como lo que es: una hipótesis consoladora que recurre a metáforas. Confiar en que una mano invisible pero inteligente rige el movimiento de la multitud empieza por ser una concesión excesiva a la fantasía omnipotente de dominación. Reducir la esfera de la política al ámbito pre-racional de las emociones que se contagian de forma viral significa disponerlas para su manipulación tecnopolítica. Ello abre las puertas a un nuevo Leviatán.

Confiar en que el sistema autopoiético trabaja a nuestro favor generando nuevas oportunidades para lo común sería un acto de fe. Creer que las leyes del sistema-red o del sistema económico y político obedecen a una cierta astucia de la razón, sería como seguir confiando en que Dios escribe derecho con renglones torcidos. Confiar en esta mano invisible del sistema regido por una teleología inmanente significaría regresar a la teología. Juan Martín Prada lo ha advertido al mencionar la metáfora que Walter Benjamin propuso para poner en cuestión el dogma marxista del materialismo histórico (Martin Prada, 2008). Dar por supuesto, por ejemplo, que la web 2.0 funciona como un software biónico con inteligencia propia sería como caer en la trampa del autómata de Kempelen construido en 1770. Este autómata jugaba al ajedrez y parecía tener inteligencia artificial, pero en realidad era movido por un enano jorobado que se escondía en el interior del mecanismo. El materialismo histórico era para Benjamin como el falso autómata de Kempelen guiado por el enano de la teología. Como ocurría en los tiempos de Benjamin, hoy también la teología es pequeña y fea de manera que, tal como ocurría con el enano jorobado de Kempelen, no podía dejarse ver. Hoy debemos estar atentos a que este enano no se esconda bajo el disfraz de la biología y la teoría de sistemas. 


\section{Referencias}

Arquilla, J. and Ronfeldt, D. (2001), Networks and Netwars: The Future of Terror, Crime, and Militancy, RAND. Trad. esp. Redes y guerras en red: el futuro del terrorismo, el crimen organizado y el activismo político, Madrid, Alianza, 2003.

Damasio, A. (2003), En busca de Spinoza: neurobiología de la emoción y los sentimientos, Barcelona, Crítica.

Domínguez, N. (2014a), «Tus neuronas mejorarán las redes que mueven el mundo» en Materia, suplemento de ciencias de El País, 01/10/014. http://elpais.com/elpais/2014/10/01/ ciencia/1412178621_038401.html [Consulta: 21 de junio de 2015].

Domínguez, N. (2014b), «Tenemos que explicar cómo una red de neuronas tontas es capaz de producir inteligencia» en Materia, suplemento de ciencias de El País, 16/07/2012 [http://esmateria.com/2012/07/16/tenemos-que-explicar-como-una-red-de-neuronastontas-es-capaz-de-producir-inteligencia/] [Consulta: 21 de junio de 2015].

Granovetter, M. (1974), Getting A Job: A Study of Contacts and Careers. Cambridge Mass, Harvard University Press.

Hardt, M. y Negri, A. (2004), Multitud. Guerra y democracia en la era del imperio, Madrid, Debate.

Hölldobler, B.; Wilson, E. O. (1990), Viaje a las hormigas, Barcelona, 1996.

Laclau, E. (2005), La razón populista. Madrid, Fondo de Cultura Económica.

Martín Prada, J. (2008), «La creatividad de la multitud conectada y el sentido del arte en el contexto de la Web 2.0» en Estudios visuales: Ensayo, teoría y crítica de la cultura visual y el arte contemporáneo, $\mathrm{n}^{\circ} .5$.

Maturana, H.R. y Varela F.J. (1973), Autopoiesis and Cognition: The Realization of the Living. Boston Studies in the Philosophy of Science. D. Reidel Publishing. Co

Negri,A. (2000), Kairos, Alma Venus, Multitudo, Roma, Manifestolibri; trad. cast. En Fábricas del sujeto. Ontología de la subversión, Madrid, Akal, 2006.

Negri, A. (2005), «El arte y la cultura en la época del Imperio y en el tiempo de las multitudes» [en línea ] Ediciones simbióticas. Dirección URL: http://edicionessimbioticas.info/ El-arte-y-la-cultura-en-la-epoca. [Consulta: 24 de junio de 2015]. Publicado posteriormente en Movimientos en el Imperio: pasajes y paisajes, Paidós, 2006.

Rancière, J. (2002), «Peuple ou multitude. Entretien avec Eric Alliez», Multitudes $\mathrm{n}^{\circ} 9$, mayo-junio de 2002 http://www.multitudes.net/Peuple-ou-multitudes/. [Consulta: 24 de junio de 2015].

Rheingold, H. (2004), Multitudes inteligentes: la próxima revolución social. Madrid, Gedisa.

Toret, J. (coord.) (2013), Tecnopolítica: la potencia de las multitudes conectadas. El sistema red 15M, un nuevo paradigma de la política distribuida, Barcelona, IN3 Internet Interdisciplinary Institute, Universitat Oberta de Catalunya.

Virno, P. (2003), Gramática de la multitud: Análisis de las Formas de vida contemporáneas, Madrid, Traficantes de sueños. 